\title{
MAGNETIC RESONANCE IMAGING OF SOLVENT TRANSPORT IN POLYMER NETWORKS
}

\author{
Robert E. Botto and George D. Cody \\ Chemistry Division, Argonne National Laboratory
}

The spectroscopic technique of magnetic resonance imaging (MRI) has recently provided a new window into transport of solvents in polymer networks. Diffusion of solvent as a rate-controlling phenomenon is paramount to understanding transport in many important industrial and biological processes, such as upgrading fossil fuels, film casting and coating, development of photoresists, design of drug-delivery systems, development of solvent resistant polymers, etc. By MRI mapping the migration of solvent molecules through various polymer specimens, researchers Robert Botto and George Cody of Argonne National Laboratory, with support from the Division of Chemical Sciences at DOE, were able to characterize and distinguish between different modes of transport behavior associated with fundamentally different types of polymer systems. The method was applied to rubbers, glassy polymers, and coals. In polymers shown to undergo a glass transition from a rigid to rubbery state, a sharply defined solvent front was observed that propagated through specimens in the manner of a constant velocity shock wave. This behavior was contrasted with a smooth solvent concentration gradient found in polymer systems where no glass transition was observed. The results of this analysis have formed the basis of a new model of anomalous transport in polymeric solids and are helping to ascertain fundamental information on the molecular architectures of these materials.

\section{DISCLAIMER}

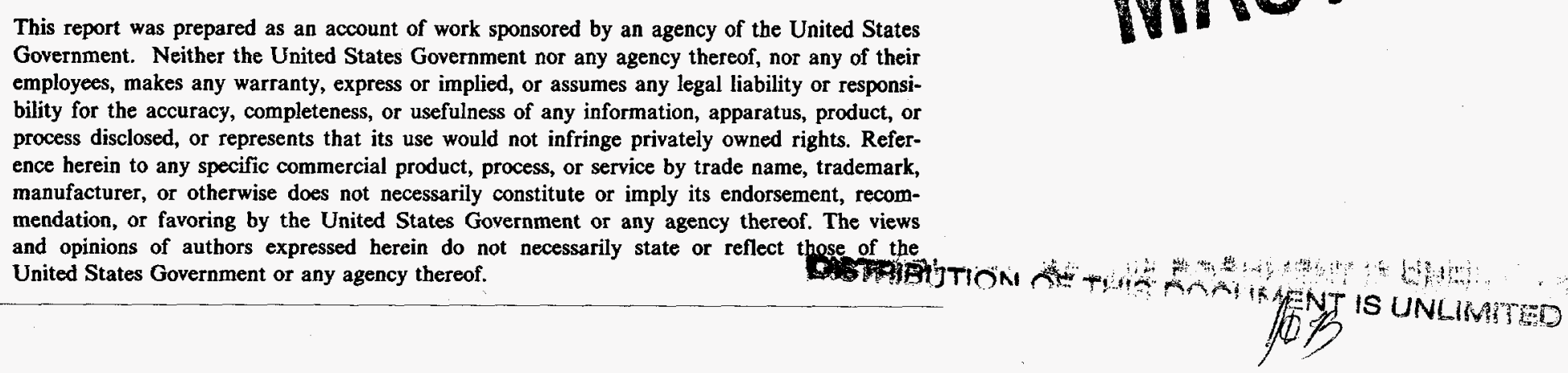

This report was prepared as an account of work sponsored by an agency of the United States employees, makes any warranty, express or implied, or assumes any legal liability or responsibility for the accuracy, completeness, or usefulness of any information, apparatus, product, or process disclosed, or represents that its use would not infringe privately owned rights. Reference herein to any specific commercial product, process, or service by trade name, trademark, manufacturer, or otherwise does not necessarily constitute or imply its endorsement, recommendation, or favoring by the United States Government or any agency thereof. The views and opinions of authors expressed herein do not necessarily state or reflect those of the United States Government or any agency thereof.

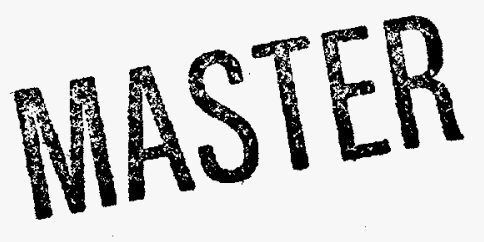




\section{DISCLAIMER}

Portions of this document may be illegible in electronic image products. Images are produced from the best available original document. 


\title{
MAGNETIC RESONANCE IMAGING OF SOLVENT TRANSPORT \\ IN POLYMER NETWORKS
}

\author{
Robert E. Botto and George D. Cody \\ Chemistry Division \\ Argonne National Laboratory \\ Argonne, IL 60439
}

Researchers in the Chemistry Division at Argonne National Laboratory have employed magnetic resonance imaging (MRI) as an effective tool to investigate the phenomenon of nonFickian or case II solvent transport in glassy polymeric networks near their glass to rubber transition. By resolving the spatial distribution of mobile solvent protons with MRI, ANL researchers are able to distinguish between Fickian transport and anomalous transport mechanisms in rubber, glassy polymer and coal specimens. The results of this analysis form the basis of a model of anomalous transport in macromolecular solids which couples diffusion with the kinetics of a first order phase transition of the network. The determination of this phase transition parameter yields fundamental information on the molecular structure of these materials.

Samples used in MRI experiments were rectangular $2 \times 2 \times 1 \mathrm{~mm}$ specimens of isobutyl rubber swollen with toluene, polyethylmethacrylate swollen with methanol and a high-volatile bituminous coal (APCS No. 4) swollen with pyridine. All images were acquired on a 2.3 Tesla NMR spectrometer fitted with a home-built probe and imaging accessory. A two-dimensional spin-echo imaging pulse sequence was implemented for phase encoding the spatial information concurrent with static field gradients of $30 \mathrm{G} / \mathrm{cm}$. The images were reconstructed by conventional Fourier transform techniques to a spatial resolution of $40 \mu \mathrm{m}$. 
Figure 1 presents transient images together with one-dimensional projections for each of the three macromolecular systems. The left column illustrates the swelling behavior of isobutyl rubber in toluene. In the case of a rubbery material, the transport behavior is anticipated to be Fickian. Analysis of the dynamic behavior of the isobutyl rubber confirms this: during the swelling interval a steep solvent gradient observed in the frame rapidly evolves into a smooth and shallower gradient indicative of a transport mechanism which is essentially Fickian.

The middle column illustrates the swelling behavior of PEMA in methanol. Clearly evident is a sharply defined solvent front which separates a swollen region from the glassy core. Swelling is essentially complete when the solvent fronts meet at the object center. In general, this behavior is typical of all polymers which pass through a glass to rubber transition during solvent uptake. The term case II has been used to describe such transport phenomena. Analysis of the transport of pyridine during the swelling of a sample of high volatile bituminous coal (right column) clearly reveals a sharp concentration profile during the uptake process which is indicative of case II type transport behavior.

In order to quantify the transient aspects of case II transport, a phenomenological transport model was designed which incorporates the essential characteristics of swelling of materials that exhibit a glass transition accompanying solvent uptake. In the glassy state the characteristic relaxation time for diffusion is very long relative to the relaxation time for molecular motion. In the rubbery state, however, diffusion is very rapid relative to molecular relaxation. The point of inversion in the relative magnitudes of the characteristic relaxation times occurs when crossing the phase boundary from the glassy to the rubbery state. 
The presence of this osmotic stress is a thermodynamic driving force for rapid expansion at the phase boundary. Consequently, the rate of relaxation in the rubbery region drives the diffusion in the glassy region.

Any useful model constitutes a balance between the need to accurately describe a physical process and the desire to remain simple with a minimum number of parameters. Ideally, these parameters have a direct connection with fundamental molecular scale characteristics of the macromolecule. In the case of solvent transport in a system undergoing a glass transition, the uptake behavior can be defined using three parameters: a characteristic cooperative diffusion coefficient, $D_{c}$, governing dilation of the network; a molecular relaxation rate constant, $\beta$, which is given by the relationship $\beta=K_{o s} / \eta_{1}$, where $\eta_{1}$ is the bulk viscosity and $K_{o s}$ is the osmotic modulus; and a critical solvent concentration, $\mathrm{v}_{2}{ }^{*}$, above which there is a transformation of the network from a glass to a rubber.

Figure 2 illustrates the time dependent uptake, $L / L_{0}$, vs. the square root of dimensionless time, $\tau$, for PEMA and the hv bituminous A coal. Depending on the magnitude of $\beta$, the characteristic shape of the uptake curve plotted as normalized dilation vs. the square root of dimensionless time is observed to evolve from an essentially convex shape at high values to sigmoid shaped uptake curve at the lower values. The convex curves are indicative of constant velocity of solvent front with time; this is consistent with case II behavior and clearly distinguishable from Fickian transport behavior. Quantifying these parameters and searching for the relationship between molecular structure and transport behavior will be the focus of future work. 

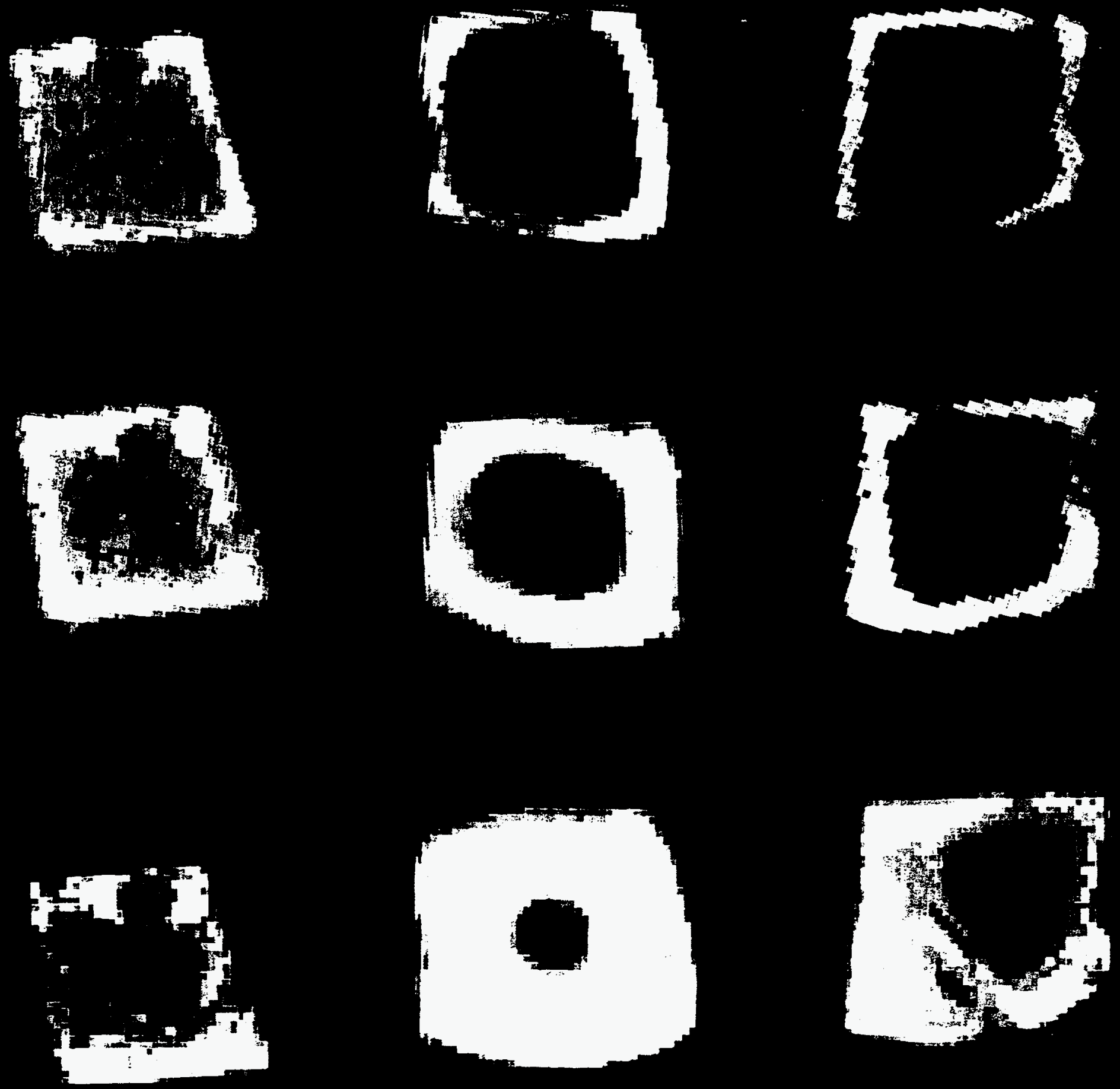

Figure 1. 2-D transient proton NMR images and 1-D projections of solvent trunspori in three mucromolecular networks: (left column) toluene in isobutyl rubber. middle column, methanol in polyethylmethacrylate. and right column, pyridine in hy bituminous $A$ vitrain. 

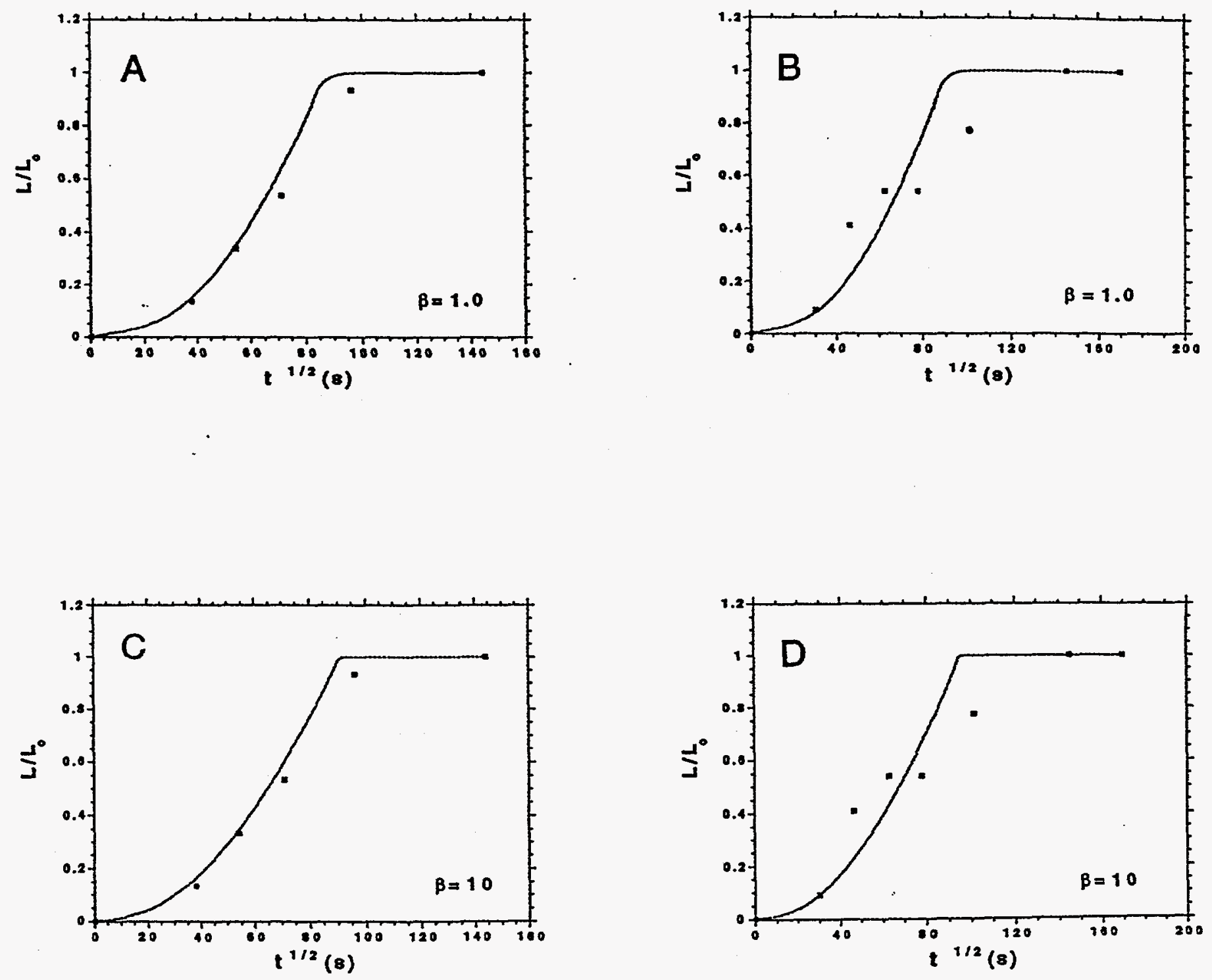

Figure 2. Dilation data for hvA bituminous vitrain swollen in pyridine and polyethylmethacrylate (PEMA) swollen in methanol fit to case $\Pi$ model with $C^{*}=0.25$ : (A) PEMA, $\beta=1.0$; (B) vitrain, $\beta=1.0$; (C) PEMA, $\beta=10$; (D) vitrain, $\beta=10$. 